\title{
Melihat Wanita dengan Perut Berlemak
}

I Gede Made Surya Darma

I Gede Made Surya Darma adalah pelukis, lulusan ISI Yogyakarta, founder Lepud Art Management. Ia aktif menggairahkan seni rupa Bali di masa pandemi. Baru-baru ini ia memimpin Art Camp 2021 (Wianta Foundation, Baturiti Tabanan), Out of the Box (Timeless Art Exhibition, Kuta, 2021), dan melakukan performance art "Blind In Paradise" (Griya Santrian Hotel Sanur, 2021).

\section{Pendahuluan}

Pada masa pandemi walau dengan keterbatasan, di Bali banyak dilakukan kegiatan pameran seni rupa yang disesuaikan dengan protokol kesehatan, entah itu secara online maupun offline. Pada tanggal 16 Oktober 2021 ada pembukaan pameran tunggal lukisan Syakieb Sungkar yang mengambil tema "Retro Expressionism, Painting Reenactment" dikuratori oleh Asmudjo Jono Irianto dan dibuka oleh Goenawan Mohamad di galeri Titik Dua, Jl. Cok Rai Pudak No.48, Peliatan, Ubud, Kabupaten Gianyar, Bali, dengan memamerkan 16 lukisan. Pameran tersebut berlangsung hingga 6 November 2021.

Nama Syakieb Sungkar sudah tidak asing lagi di kalangan dunia seni di Indonesia, beliau adalah seorang kolektor lukisan, dan pebisnis, juga pernah menjadi juri di Bandung Contemporary Art Award (BaCAA), serta menjadi anggota Persatuan Pecinta Seni Indonesia (PPSI). Beliau juga aktif di dalam kegiatan sosial kemasyarakatan, yaitu Gerakan Indonesia Kita (GITA). 
Namun di balik penyelenggaraan pameran tersebut, ternyata banyak selentingan tentang pameran beliau. Suaranya beragam seperti: Kok kolektor dan art dealer melukis, lalu seniman ngapain? Apa karena sahabatnya, sastrawan Goenawan Mohamad, melukis juga? Ibarat kata - pedagang tahu yang ikut bertani menanam kedelai sendiri, dan diolah menjadi tahu kemudian dijual sendiri pula - tidak etis dong, ujar mereka. Ada pula yang mengatakan jangan-jangan dia pakai artisan, mosok tiba-tiba bisa melukis (artisan adalah istilah bagi pelukis yang jasanya mengerjakan lukisan untuk orang lain).

Selentingan itu terjadi pula di akun media sosial dengan kalimat seperti ini "Ketika wartawan sibuk nyambi jadi pelukis dan memamerkan lukisannya, kolektor pun asyik melukis dan memamerkan karyanya di ruang publik. Bagaimana kalau nanti kurator juga berhasrat jadi pelukis? Siapa yang mau nulis pameran seni rupa, siapa lagi yang mau membeli lukisan, dan siapa lagi yang mau repot jadi kurator?" Fenomena ini menjadi menarik! Ada pula komentar dalam filosofi pedagang bakso "digawe dewe, dicicipi dewe, didol dewe, ora payu pangan dewe". Dan komentar lainnya, "wah kolektor sekarang jadi pelukis juga, Oei Hong Djien kapan ikut melukis? Juga muncul status di media sosial dengan kalimat, "memang kolektor boleh melukis?" yang kemudian menjadi perdebatan panjang. Selain itu banyak juga yang mendukung dengan menyatakan pamerannya bagus, demikian pula pengambilan ide dan teknik melukisnya, disertai ucapan selamat dan sukses, hal itu banyak dituliskan di beranda media sosial dari para seniman dan pecinta seni yang menyaksikan pameran tersebut.

\section{Picasso dan Perut Berlemak}

Beberapa jam sebelum pameran, saya mendatangi galeri Titik Dua untuk melihat langsung lukisannya di sana. Saya menyaksikan ada beberapa kawan ketika saya kuliah di Fakultas Seni Rupa ISI Yogyakarta, menjadi objek lukisan Syakieb Sungkar. Juga salah satu kolektor karya saya, Dedy Kusuma, ada dalam objek lukisan tersebut. Beberapa objek yang dilukis Syakieb, wajahnya sangat familiar untuk saya simak. Saya kemudian mendatanginya yang kebetulan sedang asik minum kopi bersama Asmudjo 
yang menjadi kurator pameran tersebut, di situ ada Goenawan Mohamad, dan Kemalezedine Zubir sebagai organizer pameran.

Saya mengorek kembali cerita tentang ayahnya yang pada tahun 1975 menghadiahi Time Magazine. Di majalah itu dibahas lukisan kubisme Pablo Picasso yang meledak di pasaran, harganya menjadi fantastis. Sementara ayahnya sebagai pekerja kantoran, pengagum Dullah dan Basoeki Abdullah yang melukis dengan gaya realisme teratur, dan suka diminta atasannya untuk mendesign label dari produk minuman, tidak mengerti mengapa lukisan corat-coret berbentuk kotak-kotak itu begitu disukai orang. Sejak itu Syakieb mulai banyak membaca ihwal lukisan, dan mulai rajin menggambar dengan pensil, crayon, tinta dan cat air. Ia menjadi terbiasa meniru-niru Picasso dan Salvador Dali.

Goenawan ikut bertanya tentang ide lukisan telanjang yang berjudul "Make Up". Lukisan berukuran 120 x $145 \mathrm{~cm}$ itu menggambarkan perempuan dengan perut dan pinggang yang lipatan lemaknya jelas terlihat. Si model yang minta dilukis marahmarah, karena tidak mau dirinya dilukis dengan kenyataan seperti itu, ia ingin dilukis lebih langsing. Bagi Syakieb, melukis dengan menonjolkan bagian tersebut adalah suatu penghormatan untuk tubuh. Bahwa semua bagian tubuh memiliki sisi menariknya, karena kecantikan itu adalah bahasa universal yang tidak bisa hanya dinilai dengan ukuran bentuk. Semua unsur tubuh memiliki kelebihan dan daya tarik masingmasing.

Ketika Syakieb melanjutkan kuliahnya di ITB ia berkenalan dengan karya-karya perupa Indonesia yang dipengaruhi oleh aliran kubisme seperti A.D Pirous, Ahmad Sadali dan Mochtar Apin. Setelah lulus ia mulai mengoleksi lukisan. Awalnya ia mengoleksi lukisan-lukisan Bali yang menurutnya unik dan tiada duanya di dunia, dan juga mengoleksi lukisan mazhab Bandung, berlanjut dengan karya-karya old master dan Mooi Indie serta karya-karya kontemporer. Ketika pada tahun 2006 hingga 2008 terjadi booming seni rupa, ia mengetahui bahwa koleksi ternyata bisa dijual kembali. Sejak itu ia terlibat dalam bisnis seni rupa. 


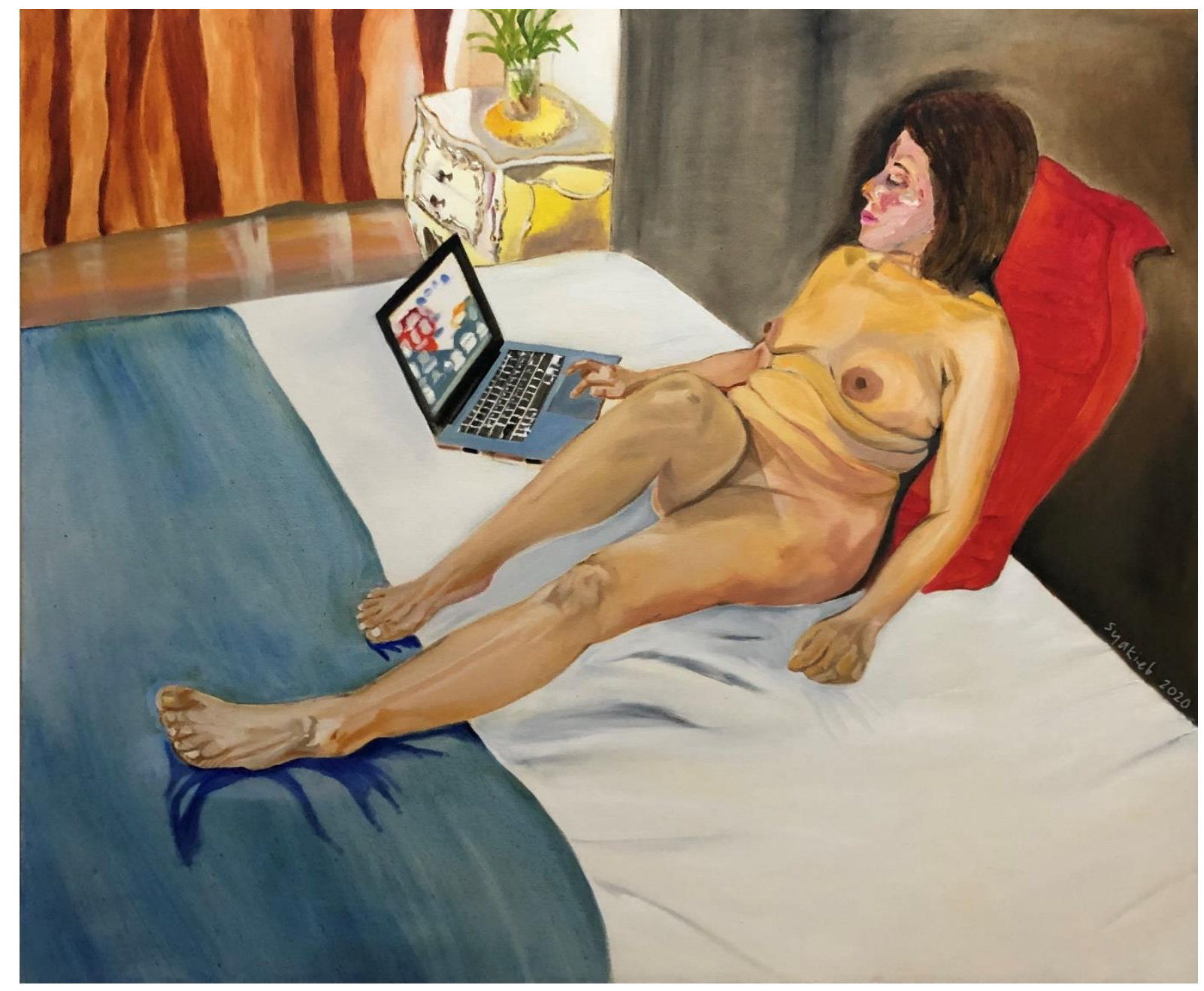

Gambar 1 - Syakieb Sungkar, “Make Up”, 2020.

Karya-karya pelukis Pablo Picasso dan S. Sudjojono yang dikaguminya, telah mempengaruhinya dalam berkarya. Nampak dalam salah satu lukisannya yang berjudul “Dialog Fatima dengan Dora Maar" berukuran 150 x $150 \mathrm{~cm}$ dengan bahan cat minyak yang dibuatnya pada tahun 2019. Idenya muncul ketika melihat lukisan Pablo Picasso yang berjudul "Portrait of Dora Maar" buatan tahun 1937 dan lukisan S. Sudjojono dengan modelnya bernama Fatima yang berjudul "Di Depan Kelambu Terbuka", bertahun 1939.

Kedua karya sezaman itu sama-sama melukiskan kekasih hati sang seniman. Namun perbedaan jarak antara Indonesia dan Perancis telah menghasilkan lukisan dengan gaya 
yang berbeda. Lukisan Dora Maar dibuat setahun setelah Pablo Picasso bertemu di lokasi syuting sebuah film Prancis yang berjudul "The Crime of Monsieur Lange". Pablo Picasso yang waktu itu berusia 55 tahun dan Dora Maar berusia 29 tahun akhirnya hidup bersama. Walau ketika itu hubungan Picasso dengan Marie-Therese yang merupakan ibu dari Maya, putrinya, masih berlangsung. Karena ketegangan dan situasi memburuk akhirnya hubungan mereka berakhir.

Berbeda halnya dengan S. Sudjojono, yang gagal menikahi kekasihnya seorang gadis Betawi bernama Yoyok. Sejak itu S. Sudjojono rajin mengunjungi tempat-tempat pelacuran dan kemudian bertemu dengan seorang Pekerja Seks Komersial (PSK) yang berasal dari Cirebon bernama Fatima, dan sudah mengganti namanya menjadi Adhesi. Fatima kabur dari rumah karena dipaksa menikahi seorang haji yang jauh lebih tua umurnya. Sampai di Batavia, Fatima terdampar di daerah Senen. S. Sudjojono seorang Marxis yang keras kepala, akhirnya mengajak Adhesi untuk menikah dan mengganti namanya menjadi Miryam, agar mirip dengan Maria Magdalena.

Dengan latar belakang adanya kedekatan kisah percintaan pada kedua lukisan yang sama-sama terlahir di masa Perang Dunia II namun dengan gaya yang berbeda. Maka muncul ide untuk mendekatkan kedua objek tersebut ke dalam satu lukisan. Mereka dibuat duduk bersanding di kursi Jawa, dengan memakai rok pendek sehingga terlihat kakinya. Bagian bawah lukisan berbeda dengan aslinya yang memakai kain batik, agar terlihat kontemporer. Kaki Dora Maar dibuat lebih putih, dan kaki Fatima dibuat lebih gelap menyesuaikan dengan warna kulit orang Indonesia. Betis dibuat lebih berotot, untuk menunjukkan wanita zaman sekarang banyak melakukan aktivitas Gym.

\section{Gay dan Jukstaposisi}

Selanjutnya adalah lukisan yang berjudul "Di Kolam Hockney Kami Berpose", yang di dalam karya tersebut nampak kolektor Dedy Kusuma bersama Syakieb berpose di kolam renang yang biasa menjadi objek lukisan David Hockney. Hockney adalah 
pelukis Pop Art asal Inggris yang kadang menggambarkan pasangan gay dalam karyanya. Dengan bercanda Syakieb memilih Dedy karena sering tampil keren berbusana metroseksual. Karya lain yang senafas dalam pameran ini adalah "Morning Coming through the Window" dan "Brokeback Mountain" dengan objeknya adalah Asmudjo bersama Kemalezedine.

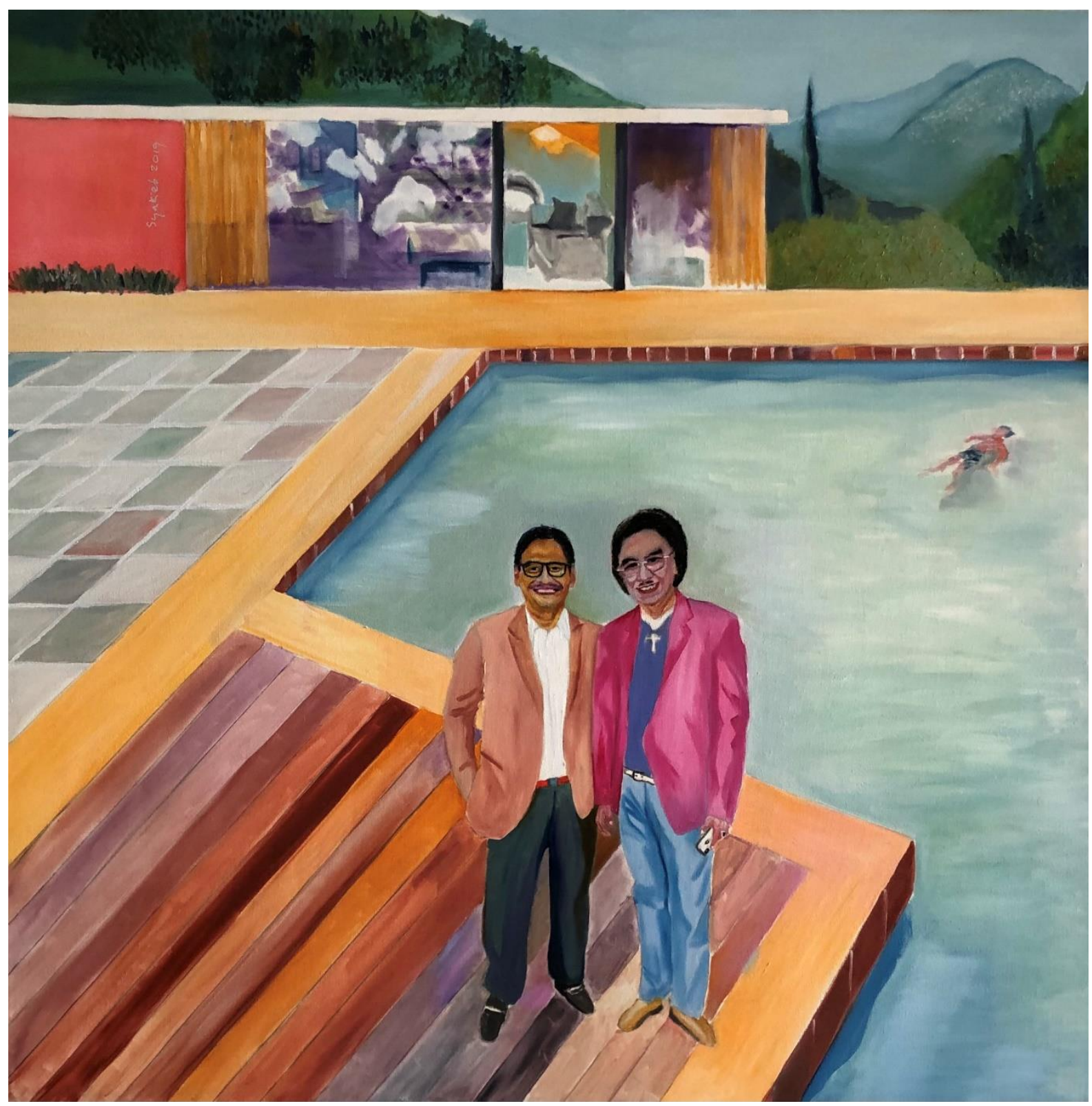

Gambar 2 - Syakieb Sungkar, “Di Kolam Hockney Kami Berpose”, 2019. 
Lain halnya dengan lukisan "Dinner with Tony". Dalam karya ini, musikus Tony Prabowo yang posisinya pada center lukisan, mengundang dinner di restoran. Nampak Tony sibuk bermain handphone ketika teman-temannya asik berbincang. Sebuah situasi kontras yang merupakan fenomena masyarakat kontemporer. Cinta gadget menarik untuk diabadikan menjadi jukstaposisi dalam lukisan tersebut.

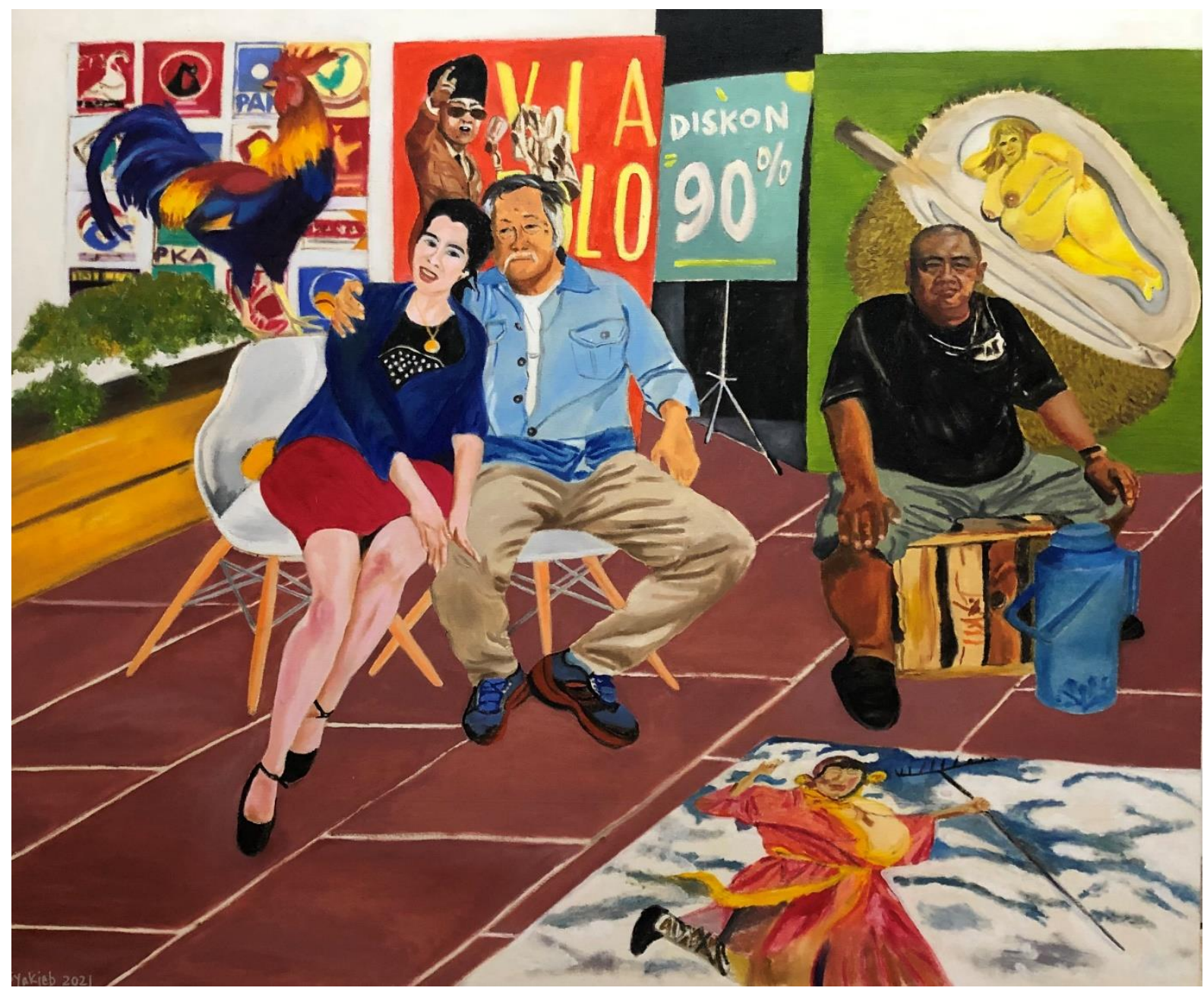

Gambar 3 - Syakieb Sungkar, “Obral Lukisan”, 2021.

Pada lukisan berjudul "Obral Lukisan" dengan ukuran 120 x $145 \mathrm{~cm}$, yang menjadi objek dalam lukisan tersebut adalah seniman lukis Yuswantoro Adi, mereka duduk berdampingan dengan Hendrotan bersama pacarnya. Ide lukisan muncul dari obrolan sebuah grup WhatsApp. Hendrotan sebagai salah satu art dealer kenamaan di Indonesia melemparkan ide untuk memasarkan seni kontemporer dengan discount besar-besaran 
sampai 90\%. Karena saat ini sangat sulit untuk menjual karya seni. Sudah pasti ide tersebut memancing keributan. Tentu seniman akan merasa keberatan dengan hal tersebut. Seniman yang pada awalnya karyanya dihargai Rp 100 juta,- akan didiskon menjadi 10 juta saja, dan sudah pasti upaya ini akan merugikan reputasi pelukis. Namun dalam lukisan, Syakieb menggambarkan seniman dan art dealer bekerja sama mengobral lukisan. Walau berkolaborasi, wajah Yuswantoro Adi dibuat dengan ekspresi bermuram durja, duduk di atas krat minuman dan termos di sampingnya. Sementara Hendrotan digambarkan tenang-tenang saja sambil memeluk pacarnya.

Selain tokoh-tokoh seperti Goenawan Mohamad dan Wiyu Wahono, Syakieb juga melukis Bubun, sopir Goenawan Mohamad yang lagi santai di bengkel Salihara menikmati istirahat dengan sandal jepit, di depan tumpukan speaker yang sedang diperbaiki.

\section{Penutup}

Syakieb Sungkar juga aktif di media sosial. Menurutnya, postingan di media sosial juga merupakan karya seni, karenanya ia memanaje kontennya. Terlihat ia tidak bermain dengan pencitraan diri agar menjaga image terus bagus. Ia tidak penuh kepalsuan, semua ditampilkan apa adanya. Pada postingannya terdapat kombinasi konten lucu, info, politik, karya seni dan kehidupan pribadinya.

Keraguan khalayak mengenai Syakieb menggunakan artisan dalam menyelesaikan lukisannya terjawab dengan ia berkunjung ke Devfto printmaking di Sika Gallery, sehari setelah pembukaan pameran, bersama Goenawan Mohamad. Di Devfto, Goenawan melukis wajah dan Syakieb membuat lukisan perempuan, nampak jelas kekuatan garis dan spontanitas goresan mereka.

Fenomena melukis yang bukan profesi sebenarnya banyak terjadi di berbagai bidang pekerjaan, seperti: Paul McCartney, gitaris The Beatles juga melukis. Selain pandai 
melukis, Paul juga menggemari karya David Hockney, Andy Warhol dan Eduardo Paolozzi. Presiden Bush juga melukis. Ia banyak melukis para veteran militer Amerika yang terluka. Demikian pula Presiden SBY ikut melukis. Ia sempat viral di media sosial. Contoh-contoh lain masih banyak. Jadi hal ini bukanlah fenomena baru tentunya.

Untuk menjadi kontemporer, Syakieb melukiskan Fatima dengan rok pendek, dan pewarnaan tidak dibuat sebagaimana aslinya. Namun sampai sekarang istilah seni kontemporer masih sulit dirumuskan. Ketika booming seni rupa 2006 - 2008, lukisan yang muncul ketika itu seringkali mempunyai kemiripan dengan karya kontemporer seniman China seperti Yue Minjun, Fang Lijun, Wang Guangyi, Xue Jiye, dan Zhou Chunya. Hal itu membuat saya bertanya-tanya. Barangkali ukuran kontemporer itu hanya dibuat demi kebutuhan market agar seni rupa menjadi mahal di bursa lelang karena sudah sesuai dengan ukuran seni kontemporer Barat. Namun dalam pengamatan saya, Syakieb terlihat tidak peduli dengan market. Ia menjadi kontemporer dengan gayanya sendiri: lingkungan dan peristiwa dalam kehidupannya sehari-hari dituangkannya dalam kanvas, dengan kejujuran dan gaya jenaka. 